Article

\title{
Xylitol Affects the Intestinal Microbiota and Metabolism of Daidzein in Adult Male Mice
}

\section{Motoi Tamura *, Chigusa Hoshi and Sachiko Hori}

National Food Research Institute, National Agriculture and Food Research Organization, Tsukuba, Ibaraki 305-8642, Japan; E-Mails: chig3@affrc.go.jp (C.H.); vets@affrc.go.jp (S.H.)

* Author to whom correspondence should be addressed; E-Mail: motoita@affrc.go.jp; Tel.: +81-298-38-8089; Fax: +81-298-38-7996.

Received: 30 August 2013; in revised form: 26 November 2013 / Accepted: 28 November 2013 / Published: 10 December 2013

\begin{abstract}
This study examined the effects of xylitol on mouse intestinal microbiota and urinary isoflavonoids. Xylitol is classified as a sugar alcohol and used as a food additive. The intestinal microbiota seems to play an important role in isoflavone metabolism. Xylitol feeding appears to affect the gut microbiota. We hypothesized that dietary xylitol changes intestinal microbiota and, therefore, the metabolism of isoflavonoids in mice. Male mice were randomly divided into two groups: those fed a $0.05 \%$ daidzein with $5 \%$ xylitol diet (XD group) and those fed a $0.05 \%$ daidzein-containing control diet (CD group) for 28 days. Plasma total cholesterol concentrations were significantly lower in the XD group than in the CD group $(p<0.05)$. Urinary amounts of equol were significantly higher in the XD group than in the CD group $(p<0.05)$. The fecal lipid contents $(\%$ dry weight) were significantly greater in the XD group than in the CD group $(p<0.01)$. The cecal microbiota differed between the two dietary groups. The occupation ratios of Bacteroides were significantly greater in the $\mathrm{CD}$ than in the XD group $(p<0.05)$. This study suggests that xylitol has the potential to affect the metabolism of daidzein by altering the metabolic activity of the intestinal microbiota and/or gut environment. Given that equol affects bone health, dietary xylitol plus isoflavonoids may exert a favorable effect on bone health.
\end{abstract}

Keywords: xylitol; equol; daidzein; mice; intestinal microbiota 


\section{Introduction}

Xylitol is classified as a sugar alcohol and used as a food additive and in medications. It has been reported that xylitol is a suitable component of a diabetic diet [1] and intake of xylitol may be beneficial in preventing the development of obesity and metabolic abnormalities in rats with diet-induced obesity [2].

It has been suggested that xylitol is a good source of energy of the rats treated with $\mathrm{CCl}_{4}$ (carbon tetrachloride) because xylitol is more efficiently oxidized to $\mathrm{CO}_{2}$ than glucose in the livers treated with $\mathrm{CCl}_{4}$ [3]. It has been reported that xylitol restricted the ovariectomy-induced reduction in bone density, in bone ash weight and in concentrations of humeral calcium and phosphorus in ovariectomized (ovx) rats [4]. Furthermore, trabecular bone loss in ovx rats was significantly decreased by dietary xylitol [4]. It has been further reported that xylitol played a protective role against osteoporosis [5]. Xylitol administration has shown improvements in bone biochemical properties [6] and retards the ovariectomy-induced increase of bone turnover in rats [7]. The stimulation of calcium (Ca) absorption in male rats after feeding diets containing xylitol has been elucidated in [8]. Thus, xylitol has favorable effects on bone metabolism.

Isoflavones are a class of phytoestrogens because they bind to the estrogen receptors, albeit weakly compared to endogenous estrogens [9]. It has been suggested that the preventive effect of daidzin, genistin and glycitin significantly prevented bone loss in ovx rats at a dose of $50 \mathrm{mg} / \mathrm{kg} / \mathrm{day}$, like estrone [10]. It has been reported that genistein was slightly lower in estrogenic potency than equol with an $\mathrm{EC}_{50}$ of $0.5 \mu \mathrm{M}$ but significantly more potent than the structurally similar compounds daidzein and biochanin A $(p<0.01)[11]$.

Human gastrointestinal bacteria seem to play an important role in isoflavone metabolism [12-16]. Equol is a metabolite of daidzein produced by intestinal microbiota [17]. The chemical structure of daidzein, equol and xylitol is shown in Figure 1. It has also been suggested that the ability to produce equol or equol itself, is closely related to a lower prevalence of prostate cancer [18]. Equol is an important bacterial metabolite in the gut. However, interindividual variations in equol production have been identified. Only $30 \%$ to $50 \%$ of humans are equol producers [19].

Figure 1. Chemical structure of xylitol, daidzein and equol.<smiles>OC[C@H](O)[C@H](O)CO</smiles>

Xylitol

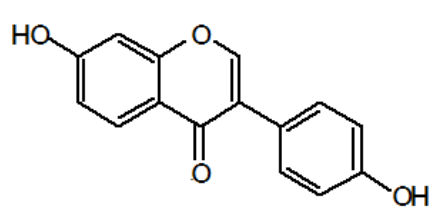

Daidzein (7-Hydroxy-3-(4-hydroxyphenyl) chromen-4-one)

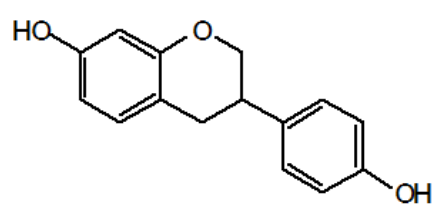

Equol(3,4-Dihydro-3-(4-hydroxyphenyl)-2H-1-benzopyran-7-ol) 
Recently, much attention has been focused on the relationship between intestinal microbiota and obesity. Studies on human volunteers have revealed that obesity is associated with changes in the relative abundance of the two dominant bacterial divisions, the Bacteroidetes and the Firmicutes [20].

On the other hand, xylitol feeding caused a clear shift in the rodent fecal microbial population from Gram-negative to Gram-positive bacteria [21]. Xylitol affects the fecal microbiota [21]. Xylitol feeding seems to affect the gut microbiota.

We tested the hypothesis that dietary xylitol changes the metabolism of isoflavonoids and intestinal microbiota in mice.

\section{Results and Discussion}

\subsection{General Observations}

No significant differences were observed between the control-daidzein (CD) and xylotol-daidzein (XD) groups in final body weight $(\mathrm{g}) \mathrm{CD}(32.2 \pm 1.1)$ and XD $(34.4 \pm 1.0)$, food consumption CD $(4.26 \pm 0.02)$ and $\mathrm{XD}(4.27 \pm 0.02)$, visceral fat $(\mathrm{g}) \mathrm{CD}(1.44 \pm 0.24)$ and $\mathrm{XD}(1.49 \pm 0.25)$, amount of feces (g/day) $\mathrm{CD}(0.34 \pm 0.01)$ and XD $(0.34 \pm 0.01)$ or liver weight $(\mathrm{g}) \mathrm{CD}(1.40 \pm 0.05)$ and XD $(1.58 \pm 0.09)$. The cecal contents were significantly higher in the XD group $(0.26 \pm 0.02)$ than in the CD group $(0.12 \pm 0.01)(p<0.01)$.

\subsection{Urinary Isoflavonoids}

Xylitol affected the amount of daidzein and its metabolites found in the urine (Figure 2). An HPLC chromatogram obtained from urine of a mouse fed the XD diet is shown in Figure 3. In our results, significant amounts of DHD (dihydrodaidzein), which is a precursor of equol, were excreted in the urine. The proposed pathway for daidzein reduction by intestinal microbiota is shown in Figure 4 .

Figure 2. Amounts of urinary isoflavonoids of mice in the control diet (CD) group and the xylitol diet (XD) group. Enzymatic hydrolysis of the urinary isoflavone glucuronides was carried out with $\beta$-glucuronidase/arylsulfatase from Helix pomatia. We measured the urinary isoflavonoids as aglycones. Values are means $\pm \mathrm{SE}(n=7)$. * Significantly different $(p<0.05)$ from the CD group. The data were analyzed using the Student's $t$-test (equol). Statistical significance was reached with a $p$ value of less than 0.05 .

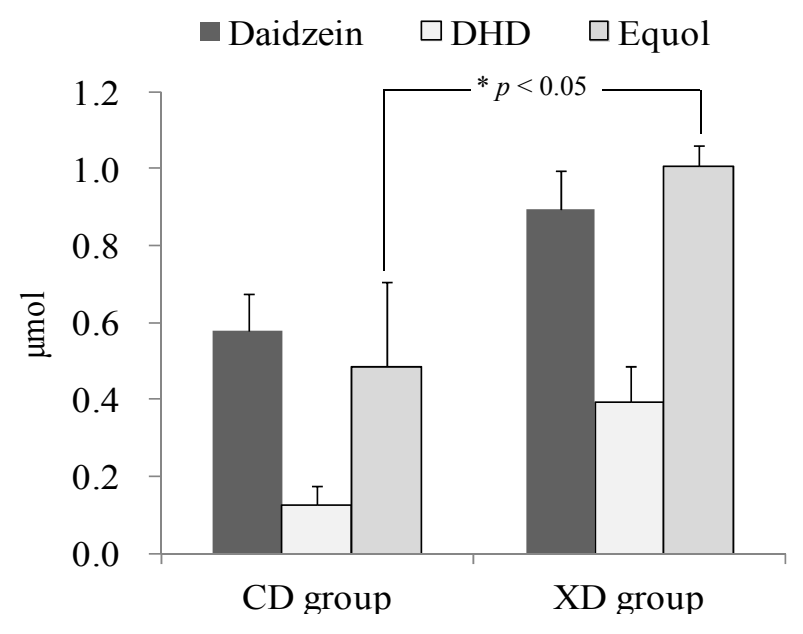


Figure 3. HPLC chromatogram of daidzein, dihydrodaidzein and equol obtained from urine of a mouse fed the XD diet at $280 \mathrm{~nm}$. Peak identity was confirmed by rechromatography with the authentic compounds.

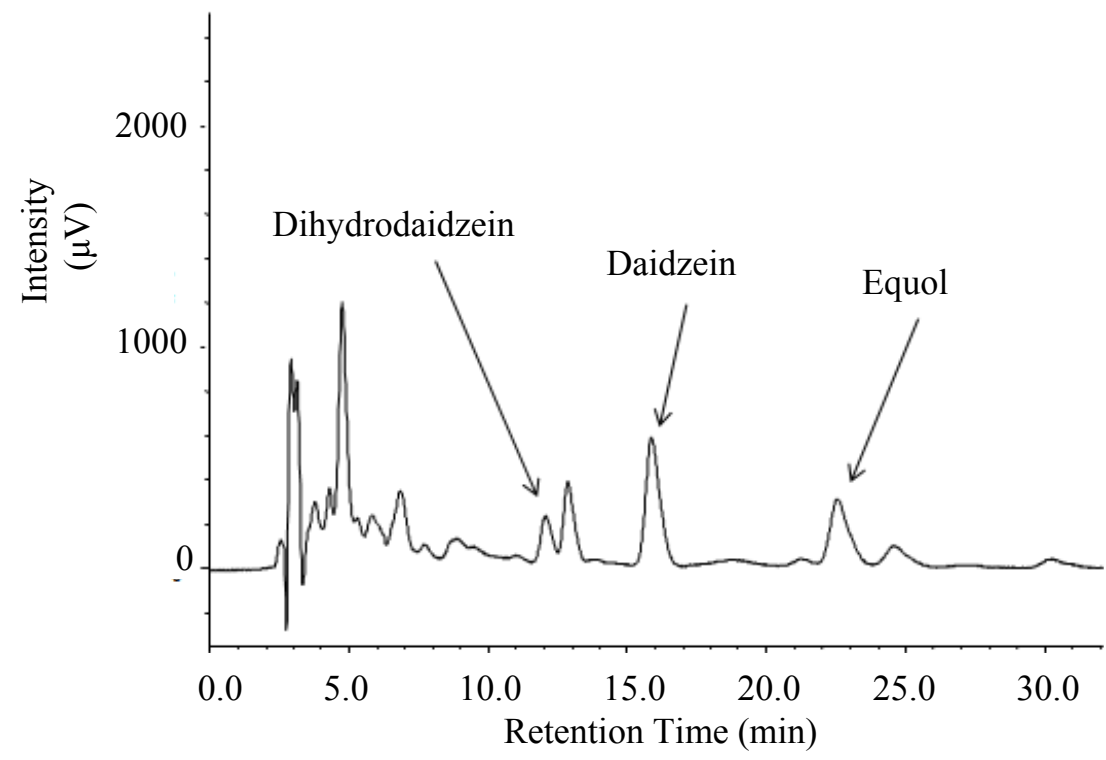

Figure 4. Proposed pathway for daidzein reduction by intestinal microbiota [22].<smiles>O=c1c(-c2ccc(O)cc2)coc2cc(O)ccc12</smiles>

Daidzein<smiles>Oc1ccc(C2COc3cc(O)ccc3C2)cc1</smiles>

Equol

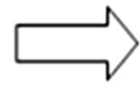<smiles>O=C1c2ccc(O)cc2OCC1c1ccc(O)cc1</smiles>

Dihydrodaidzein (DHD)

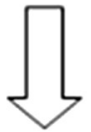<smiles>C1CCCC1</smiles>

Tetrahydrodaidzein (THD)

Average urinary amounts of daidzein and dihydrodaidzein (DHD) tended to be higher in the $\mathrm{XD}$ group than in the $\mathrm{CD}$ group. It has been reported that rat intestinal microbiota rapidly metabolized daidzein to aliphatic compounds that could not be detected by HPLC or mass spectral analysis [23]. Degradation activity of intestinal microbiota against daidzein might have differed between the two groups.

The urinary amounts of equol were significantly higher in the XD group than in the CD group $(p<0.05)$ (Figure 2). Xylitol was characterized by a significantly increased production of short-chain fatty acids (SCFA), particularly the concentration of butyrate [24]. The addition of butyrate increased the equol production in equol-producing bacteria [25]. It has been reported that butyrate increased the 
conversion ratio of daidzein to equol in equol-producing bacteria [25]. Our results suggest that dietary xylitol might induce equol production by stimulating butyrate-producing bacteria in the fecal microbiota of the mice.

On the other hand, xylitol decreased the rate of gastric emptying but concomitantly accelerated intestinal transit compared with glucose [26]. Thus, xylitol administration might alter the gut environment and metabolism of isoflavonoids. Our results suggest that dietary xylitol has the potential to affect the metabolism of equol by altering the metabolic activity of the intestinal microbiota and/or digestion and absorption of isoflavonoids.

It has been indicated that xylitol exerted beneficial effects on bone health $[4,8,27,28]$. Equol also affects the bone health $[29,30]$. It has been reported that a combination of dietary fructooligosaccharides and isoflavone conjugates increases femoral bone mineral density and equol production in ovx mice [30]. It has been suggested that $10 \mathrm{mg}$ /day of equol supplementation contributes to bone health in non-equol-producing postmenopausal women without adverse effects [31]. Dietary xylitol plus isoflavonoids may exert a synergic effect on bone health, resulting in the prevention of the osteoporosis.

\subsection{Amount of Fecal Lipid Contents}

The XD diet significantly affected the fecal lipid contents. The fecal lipid contents (\% dry weight) of feces sampled on the final days of the experiment were significantly greater in the XD group than in the CD group $(p<0.01)$, as shown in Figure 5.

Figure 5. The fecal lipid contents (\% dry weight) sampled on the final days of the experiment were significantly greater in the XD group than in the $\mathrm{CD}$ group $(p<0.01)$ Values are means \pm SE $(n=7)$. The data were analyzed using the Student's $t$-test analysis. ** Significantly different $(p<0.01)$ from the CD group.

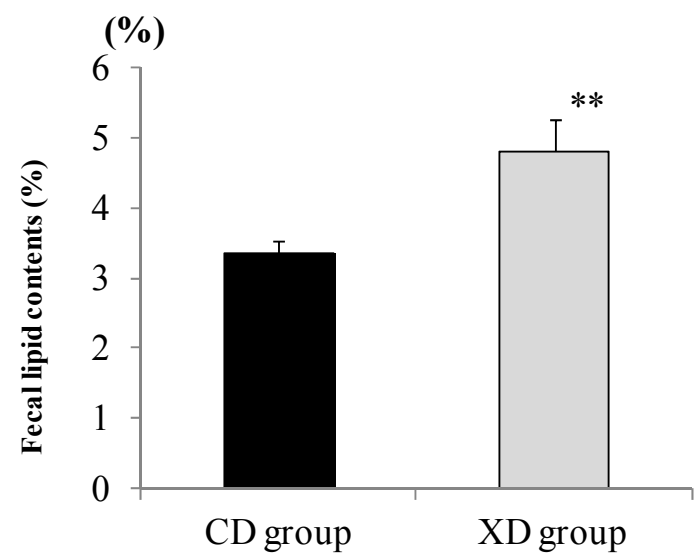

Xylitol seems to affect gut function. It has been reported that after ingestion of $25 \mathrm{~g}$ xylitol, gastric emptying was markedly prolonged in human volunteers [32]. Prolonged gastric emptying by xylitol might reduce the absorption of lipids, resulting in the increase of the fecal lipid contents in the XD group. 


\subsection{Plasma Total Cholesterol, Triglycerides, and Phospholipids}

The plasma was separated from whole blood by centrifugation and used for analysis of plasma triglycerides, total cholesterol and phospholipids. Plasma lipids are shown in Figure 6. Plasma cholesterol concentrations were modestly lower in the XD $(185.2 \pm 13.0 \mathrm{mg} / \mathrm{dL})$ than in the CD $(230.8 \pm 16.2 \mathrm{mg} / \mathrm{dL})$ group $(p<0.05)$. No significant differences in the plasma triglyceride $(\mathrm{TG})$ concentrations $(\mathrm{CD}, 146.6 \pm 26.6 \mathrm{mg} / \mathrm{dL} ; \mathrm{XD}, 146.8 \pm 14.0 \mathrm{mg} / \mathrm{dL})$ or plasma phospholipids (PL) concentrations $(\mathrm{CD}, 313.7 \pm 22.3 \mathrm{mg} / \mathrm{dL} ; \mathrm{XD}, 313.6 \pm 28.9 \mathrm{mg} / \mathrm{dL})$ were observed between the two groups.

Figure 6. Plasma total cholesterol, triglycerides (TG) and phospholipids (PL) concentrations of mice in the xylitol-daidzein (XD) and control-daidzein (CD) groups. Values are means $\pm \operatorname{SE}(n=7)$. The data were analyzed using the Student's $t$-test analysis $(p<0.05)$.

* Significantly different $(\mathrm{p}<0.05)$ from the CD group.

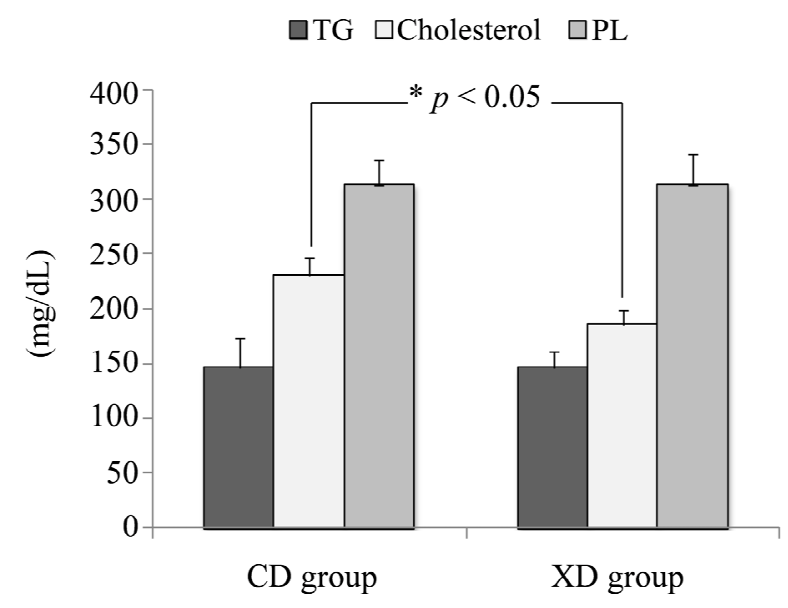

It was reported that an isoflavone aglycone-rich extract without soy protein attenuated atherosclerosis development in cholesterol-fed rabbits [33]. Dietary daidzein contained in the experimental diet affected the plasma lipids in both the CD and XD groups. However, plasma total cholesterol concentrations were significantly lower in the XD group than in the CD group. The contribution of daidzein was not evident at the plasma cholesterol level. It has been reported that xylitol-fed rats had significantly lower serum total cholesterol levels than control rats [34,35]. Dietary xylitol might have potent cholesterol-lowering effect in mice. However, no significant differences in serum triglycerides were observed between the xylitol-fed rat and control rats [34]. Though our experimental diet contained $0.05 \%$ daidzein, these results agree with ours. Plasma total cholesterol concentrations were significantly lower in the XD group than in the CD group. These results suggest that dietary xylitol has modest effects on lipid absorption in mice.

\subsection{Effects of Diet on Cecal Microbiota of Mice}

The compositions of the phylogenetic groups of cecal microbiota differed between the two dietary groups (Figure 7). The predominant operational taxonomic units (OTUs) [36], which correspond to either T-RFs (terminal restriction fragments) or T-RF clusters, were detected in the T-RFLP (terminal restriction fragment length polymorphism) profiles and used to identify phylogenetic groups of intestinal microbiota [37,38]. 
Figure 7. Composition of cecal intestinal microbiota of mice in the $\mathrm{CD}$ and $\mathrm{XD}$ groups. OTUs (operational taxonomic units), which correspond to either T-RFs (terminal restriction fragments) or T-RF clusters, detected by T-RFLP (terminal restriction fragment length polymorphism) analysis. Values are means $\pm \operatorname{SE}(n=7) . *$ Significantly different $(p<0.05)$ from the CD group. Data were analyzed using the Student's $t$-test analysis. Letters correspond to the following phylogenetic bacterial groups: (A) Bacteroides, Clostridium cluster IV (OTUs 370); (B) Clostridium cluster IV (OTUs 168, 749); (C) Clostridium cluster IX, Megamonas (OTUs 110); (D) Clostridium cluster XI (OTUs 338); (E) Clostridium subcluster XIVa (OTUs 106, 494, 505, 517, 754, 955, 990); (F) Clostridium cluster XI, Clostridium subcluster XIVa (OTUs 919); (G) Clostridium subcluster XIVa, Enterobacteriales (OTUs 940); (H) Clostridium cluster XVIII (OTUs 423, 650); (I) Bacteroides (OTUs 469, 853); (J) Bifidobacterium (OTUs 124); (K) Lactobacillales (OTUs 332, 520, 657); (L) Prevotella (OTUs 137, 317); and (M) others.

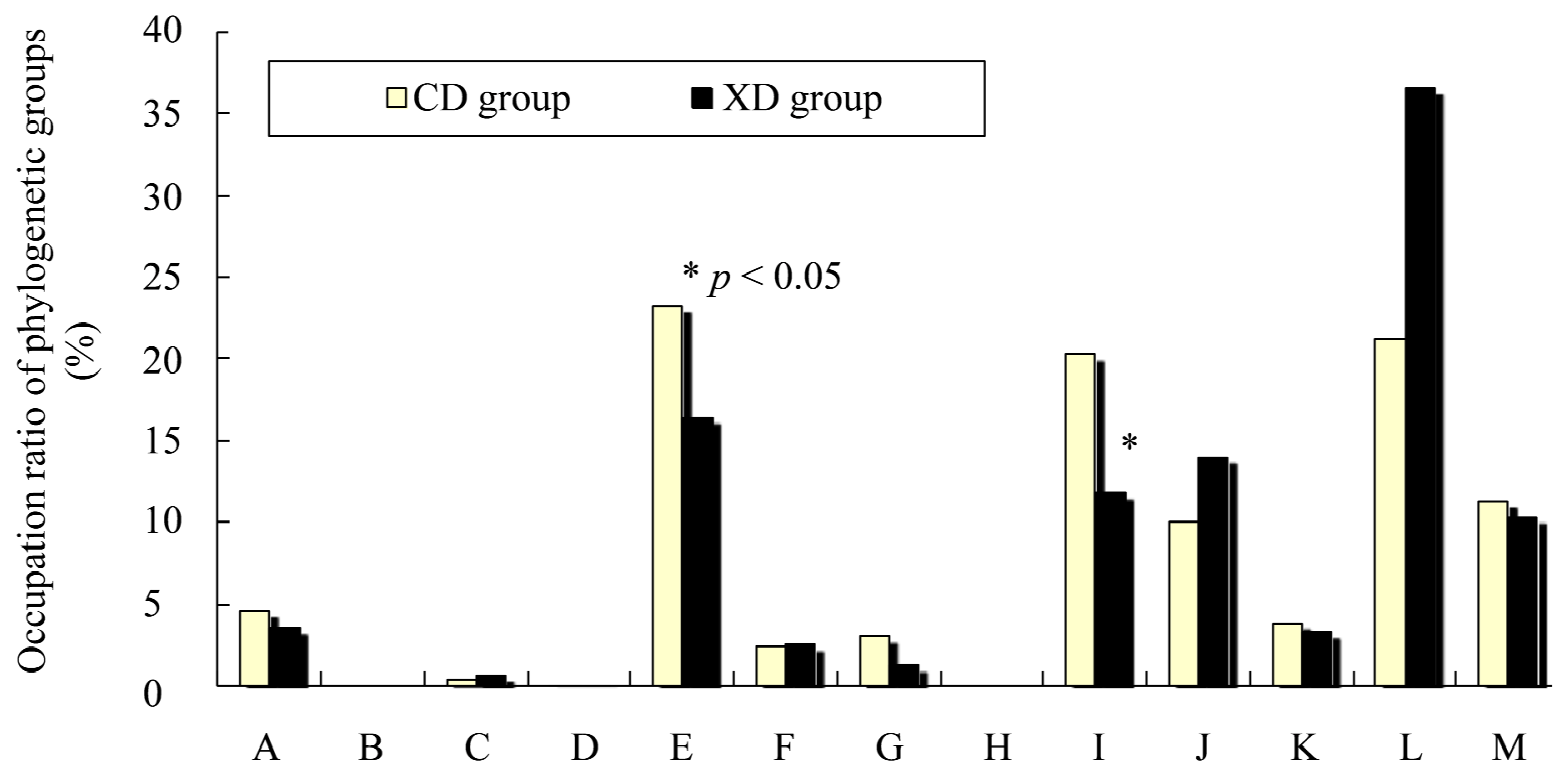

The occupation ratios of Bacteroides [operational taxonomic units (OTUs) 469, 853] were significantly greater in the $\mathrm{CD}$ than in the XD group $(p<0.05)$. Dietary xylitol-feeding may reduce Bacteroides (OTUs 469, 853). Bacteroides belongs to Gram-negative bacteria.

It has been shown that xylitol feeding caused a clear shift in rodent fecal microbial populations from Gram-negative to Gram-positive bacteria [21]. In human volunteers a similar shift was observed even after a single 30 -g oral dose of xylitol [21].

It has been confirmed that human intestinal microbiota predominantly consists of members of approximately 10 phylogenetic bacterial groups and that these bacterial groups can be distinguished by the T-RFLP system developed by Nagashima et al. [37,38]. We used this Nagashima method [37,38] although it cannot completely distinguish between Gram-negative and Gram-positive bacteria. However, in our results, the occupation ratios of Bifidobacterium tended to increase in the XD group. Bifidobacterium belongs to Gram-positive bacteria.

The occupation ratios of Prevotella tended to increase in the XD group. There are few reports with respect to the effects of dietary xylitol on Prevotella. We cannot explain this phenomenon. 
Some diets affect the composition of intestinal microbiota [39]. It has been reported that diet affects the microbiota in terms of both structure and gene expression [40]. Switching from a low-fat, plant polysaccharide-rich diet to a high-fat, high-sugar "Western" diet shifted the population of the microbiota within a single day, changed the representation of metabolic pathways in the microbiome, and altered microbiome gene expression [40]. It has been reported that dietary fat significantly affects intestinal microbiota [40,41]. In our result, the XD diet significantly affected the fecal lipid contents. Differences in lipid concentrations of the gut also might affect the composition and/or metabolic activities of intestinal microbiota.

A limitation of our study was that we could not identify what kind of intestinal bacteria were stimulated by the supplementation of dietary xylitol in vitro. Further studies are needed to clarify these effects.

\section{Experimental Section}

\subsection{Materials}

Daidzein and equol were purchased from LC Laboratories (Woburn, MA, USA). Dihydrodaidzein was purchased from Toronto Research Chemicals, Inc. (North York, ON, Canada). $\beta$-Glucuronidase type H-5 was obtained from Sigma (St. Louis, MO, USA). Xylitol was purchased from Wako Pure Chemical Industries, Ltd. (Osaka, Japan).

\subsection{Treatment of Animals}

Male Crj: CD-1 (ICR) mice (6 weeks old) were purchased from Charles River Japan, Inc. (Kanagawa, Japan). All mice were specific pathogen-free (SPF) and were housed in conventional conditions in our laboratory. The mice were randomly divided into two groups of seven animals each. The animals were housed individually in suspended stainless-steel cages with wire mesh bottoms, in a room kept at $24 \pm 0.5{ }^{\circ} \mathrm{C}$ and a relative humidity of $65 \%$, with $12 \mathrm{~h}$ periods of light and dark. Mice were fed an AIN-93M diet [42] for 9 days. After 9 days, the diet was replaced with a $0.05 \%$ daidzein (CD) diet (as control diet) or $0.05 \%$ daidzein-5\% xylitol (XD) diet, for 28 days. After 21 days from the start of the experimental diet feeding, all animals were moved to individual metabolic cages (Tecniplast S.P.A., Buguggiate, Italy). Urine was collected from all mice for $45 \mathrm{~h}$. Urinary amounts of isoflavonoids were measured. The purified diet and water were provided ad libitum. Table 1 presents the composition of each diet. Body weight and food consumption were measured during the experiment. Feces were collected during the experiment in a metabolic cage. Feces were dried with a freeze dryer (FD-1000; Tokyo Rikakikai Co., Ltd., Tokyo, Japan) for $24 \mathrm{~h}$. The trap cooling temperature was $-45^{\circ} \mathrm{C}$. After the experimental diet feeding period, the mice were anesthetized by $30 \mathrm{mg} / \mathrm{kg}$ of intraperitoneal injection of pentobarbital sodium and blood samples were taken from the abdominal aorta and placed in heparinized tubes. All mice were euthanized by $\mathrm{CO}_{2}$. The plasma was separated from whole blood by centrifugation and stored at $-80{ }^{\circ} \mathrm{C}$ until analysis of plasma lipids. The liver, visceral fat, and cecal contents were collected. Cecal contents were stored at $-80^{\circ} \mathrm{C}$ until T-RFLP analysis of intestinal microbiota. The liver samples and visceral fat were weighed. All procedures involving mice in this study were approved by the Animal Care Committee of the National Food Research Institute (Tsukuba, Japan), in accordance 
with the "Guidelines for Animal Care and Experimentation" of the National Food Research Institute, National Agriculture and Food Research Organization (NARO, Tsukuba, Japan).

\subsection{Measurement of Plasma Cholesterol, Triglycerides, and Phospholipids}

The following tests were performed with kits obtained from Wako Pure Chemical Industries Ltd. (Osaka, Japan). Total plasma cholesterol concentrations were measured using a cholesterol E-test kit based on cholesterol oxidase [43]. Plasma triglyceride concentrations were measured using a triglyceride E-test kit based on the glycerol-3-phosphate oxidase method [44]. Plasma phospholipid concentrations were measured using a phospholipid C-test kit based on the choline oxidase method [45].

Table 1. Composition of the experimental diet.

\begin{tabular}{cccc}
\hline Ingredient (g/kg Diet) & AIN-93M & CD Diet & XD Diet \\
\hline Corn starch & 465.692 & 455.692 & 405.692 \\
Casein & 140 & 140 & 140 \\
a-Corn starch & 155 & 154.5 & 154.5 \\
Sucrose & 100 & 100 & 100 \\
Lard & - & 50 & 50 \\
Soy bean oil & 40 & - & - \\
Cellulose & 50 & 50 & 50 \\
Mineral mix (AIN-93M-Mix) & 35 & 35 & 35 \\
Vitamin mix (AIN-93-Mix) & 10 & 10 & 10 \\
L-Cystine & 1.8 & 1.8 & 1.8 \\
Tert-butylhydroquinone & 0.008 & 0.008 & 0.008 \\
Choline bitartrate & 2.5 & 2.5 & 2.5 \\
Xylitol & - & - & 50 \\
Daidzein & - & 0.5 & 0.5 \\
\hline
\end{tabular}

\subsection{Measurements of Fecal Weight and Fecal Lipid Extraction}

All feces were collected during the experiment in metabolic cage. Weights of feces were measured. Feces were then dried with a freeze dryer (FD-1000, Tokyo Rikakikai Co., Ltd., Tokyo, Japan) for $24 \mathrm{~h}$. The trap cooling temperature was $-45^{\circ} \mathrm{C}$. After drying, weights of freeze-dried feces were measured. Feces were milled with a food mill (TML17; TESCOM Co., Ltd., Tokyo, Japan) for $30 \mathrm{~s}$. Fecal lipids were extracted from the fecal powder by the Bligh and Dyer method [46]. A milled feces (100 mg) was added to $1 \mathrm{~mL}$ of $0.1 \mathrm{M}$ sodium acetate buffer ( $\mathrm{pH} 5.0)$. $3.75 \mathrm{~mL}$ of chloroform:methanol $(1: 2 \mathrm{v} / \mathrm{v})$ was added to the sample. All samples were vortexed for $120 \mathrm{~s}$. Next, $1.25 \mathrm{~mL}$ of chloroform was added to the sample. All samples were vortexed for 60 s. $1.25 \mathrm{~mL}$ of $\mathrm{dH}_{2} \mathrm{O}$ was added to the sample. All samples were vortexed for $60 \mathrm{~s}$ and centrifuged at $3000 \mathrm{rpm}$ for $10 \mathrm{~min}$. The organic lower phase was removed using a Pasteur pipette and transferred to a glass test tube. The organic phase was evaporated under a gentle stream of dry nitrogen. The dried extracts were weighed. 


\subsection{Analysis of Urinary Isoflavonoids}

An enzymatic hydrolysis of the isoflavone glucuronides was used for the total isoflavone content determination in the urine samples. A total of $200 \mu \mathrm{L}$ of urine was added to $200 \mu \mathrm{L}$ of $\beta$-glucuronidase H-5 solution ( $35 \mathrm{mg} / \mathrm{mL}$; Sigma) in $0.2 \mathrm{M}$ sodium acetate buffer (pH 5.0). Next, the mixture was incubated at $37^{\circ} \mathrm{C}$ in a water bath for $3 \mathrm{~h}$, followed by treatment with $400 \mu \mathrm{L}$ of ethyl acetate, vortexing for $30 \mathrm{~s}$, and centrifugation at $5000 \times \mathrm{g}$ for $10 \mathrm{~min}$ at $4{ }^{\circ} \mathrm{C}$. The supernatants were transferred to an eggplant-type flask. The same volume as that used in the first extraction of ethyl acetate was added to the sediment, and the procedure was repeated. The supernatants from both extractions were pooled in the eggplant-type flask and evaporated completely using a rotary evaporator. The sample was then dissolved in $400 \mu \mathrm{L}$ of $80 \%$ methanol and filtered through a $0.2-\mu \mathrm{m}$ filter. Filtrates were used for HPLC analysis. For HPLC analysis, $20 \mu \mathrm{L}$ of each preparation were injected into a $250 \times 4.6-\mathrm{mm}$ Capcell Pak MG C18 5- $\mu \mathrm{m}$ column (Shiseido, Tokyo, Japan). To detect isoflavonoids, a photodiode array detector (MD-1515; JASCO, Co., Ltd., Tokyo, Japan) was used to monitor the spectral data from 200 to $400 \mathrm{~nm}$ for each peak. To measure the isoflavonoids, daidzein, DHD and equol were used as standard samples. The spectral data at $254 \mathrm{~nm}$ was used to quantify daidzein $\left(t_{\mathrm{R}} 15.8 \mathrm{~min}\right)$ and the spectral data at $280 \mathrm{~nm}$ was used to quantify equol ( $\left.t_{\mathrm{R}} 22.4 \mathrm{~min}\right)$ and $\mathrm{DHD}\left(t_{\mathrm{R}} 12.0 \mathrm{~min}\right)$. The mobile phase consisted of methanol/acetic acid/water $(35: 5: 60, v / v / v)$. The running conditions of HPLC were a column temperature of $40{ }^{\circ} \mathrm{C}$ and a flow rate of $1 \mathrm{~mL} / \mathrm{min}$ [47].

\subsection{DNA Extraction from Cecal Contents}

DNA extractions from cecal contents were conducted according to Matsuki's method [48]. Cecal samples $(20 \mathrm{mg}$ ) were washed three times by suspending them in $1.0 \mathrm{~mL}$ of phosphate-buffered saline (PBS) and centrifuging each preparation at $14,000 \times g$ to remove possible PCR inhibitors. Following the third centrifugation, the cecal pellets were resuspended in a solution containing $0.2 \mathrm{~mL}$ of PBS and $250 \mu \mathrm{L}$ of extraction buffer (200 mM Tris-HCl, 80 mM EDTA; pH 9.0) and $50 \mu \mathrm{L}$ of 10\% sodium dodecyl sulfate. A total of $300 \mathrm{mg}$ of glass beads (diameter, $0.1 \mathrm{~mm}$ ) and $500 \mu \mathrm{L}$ of buffer-saturated phenol were added to the suspension, and the mixture was vortexed vigorously for $60 \mathrm{~s}$ using a Mini Bead-Beater (BioSpec Products Inc., Bartlesville, OK, USA) at a power level of $4800 \mathrm{rpm}$. Following centrifugation at $14,000 \times g$ for $5 \mathrm{~min}, 400 \mu \mathrm{L}$ of the supernatant was collected. Phenol-chloroform-isoamyl alcohol extractions were then performed, and $250 \mu \mathrm{L}$ of the supernatant was subjected to isopropanol precipitation. Finally, the DNA was suspended in $1 \mathrm{~mL}$ of Tris-EDTA buffer. The DNA preparation was adjusted to a final concentration of $10 \mu \mathrm{g} / \mathrm{mL}$ in TE and checked by $1.5 \%$ agarose gel electrophoresis.

\subsection{PCR Conditions and Restriction Enzyme Digestion}

The PCR mixture $(25 \mu \mathrm{L})$ was composed of Ex Taq buffer (Takara Bio Inc., Otsu, Japan), $2 \mathrm{mM}$ of $\mathrm{Mg}^{2+}$, and each deoxynucleoside triphosphate at a concentration of $200 \mu \mathrm{M}$. The amount of cecal DNA was $10 \mathrm{ng}$. The primers [37] used were 5' FAM (carboxyfluorescein)-labeled 516f (5'-TGCCAGCAGCCGCGGTA-3') and 1510r (5'-GGTTACCTTGTTACGACTT-3') at a concentration of $0.10 \mu \mathrm{M}$, template DNA, and $0.625 \mathrm{U}$ of DNA polymerase (TaKaRa EX Taq; Takara Bio Inc., Otsu, 
Japan). This process was carried out using a PCR system (Dice system; Takara Bio Inc.). Amplification was performed with one cycle at $95{ }^{\circ} \mathrm{C}$ for $15 \mathrm{~min}$, followed by 30 cycles at $95{ }^{\circ} \mathrm{C}$ for $30 \mathrm{~s}, 50{ }^{\circ} \mathrm{C}$ for $30 \mathrm{~s}, 72{ }^{\circ} \mathrm{C}$ for $1 \mathrm{~min}$, and finally one cycle at $72^{\circ} \mathrm{C}$ for $10 \mathrm{~min}$. The amplification products were subjected to gel electrophoresis in $1.5 \%$ agarose followed by ethidium bromide staining. The PCR products were purified using spin columns (QIAquick; Qiagen KK, Tokyo, Japan) according to the manufacturer's instructions. The purified DNA was treated with $2 \mathrm{U}$ of BslI (New England Biolabs, Ipswich, MA, USA) for $3 \mathrm{~h}$ at $55^{\circ} \mathrm{C}[37]$.

\subsection{T-RFLP (Terminal Restriction Fragment Length Polymorphism) Analysis}

T-RFLP (terminal restriction fragment length polymorphism) analysis is based on PCR amplification of a target gene. The amplification is performed with one primer whose $5^{\prime}$ end is labeled with a fluorescent molecule. The mixture of amplicons is then subjected to a restriction reaction using a restriction enzyme. Following the restriction reaction, the mixture of fragments is separated using either capillary or polyacrylamide electrophoresis in a DNA sequencer, and the sizes of the different terminal fragments are determined by the fluorescence detector. We used this T-RFLP analysis in our experiment. The fluorescently labeled terminal restriction fragments (T-RFs) were analyzed by electrophoresis on an automated sequence analyzer (ABI PRISM 310 Genetic Analyzer; Applied Biosystems, Life Technologies Corporation, Carlsbad, CA, USA) in GeneScan mode. The restriction enzyme digestion mixture $(2 \mu \mathrm{L})$ was mixed with $0.5 \mu \mathrm{L}$ of size standards (MapMarker 1000; BioVentures, Inc., Murfreesboro, TN, USA) and $12 \mu \mathrm{L}$ of deionized formamide. The mixture was denatured at $96{ }^{\circ} \mathrm{C}$ for $2 \mathrm{~min}$ and immediately chilled on ice. The injection time was $30 \mathrm{~s}$ for analysis of T-RFs from digestion with $B s l \mathrm{I}$. The run time was $40 \mathrm{~min}$. The lengths and peak areas of T-RFs were determined with GeneMapper software (Applied Biosystems, Life Technologies Corporation). The predominant OTUs, which correspond to either T-RFs or T-RF clusters, were detected in the T-RFLP profiles and used to identify phylogenetic groups of intestinal microbiota [37,38].

\subsection{Statistics}

Data are expressed as the mean \pm standard error (SE). All data were analysed using Sigma Plot 11 (Systat Software, Inc., San Jose, CA, USA). The data were analysed with the Student's $t$-test or Mann-Whitney rank sum test. Statistical significance was reached with a $p$-value $<0.05$.

\section{Conclusions}

In conclusion, plasma total cholesterol concentrations were significantly lower in the XD group than in the CD group. Urinary amounts of equol were significantly higher in the XD group than in the CD group. The fecal lipid contents ( $\%$ dry weight) were significantly greater in the XD group than in the CD group. The cecal microbiota differed between the two dietary groups. The occupation ratios of Bacteroides (OTUs 469, 853) were significantly greater in the CD than in the XD group $(p<0.05)$. This study suggests that xylitol has the potential to affect the metabolism of daidzein by altering the metabolic activity of the intestinal microbiota and/or gut environment. Given that equol affects bone health, dietary xylitol plus isoflavonoids may exert a favorable effect on bone health. 


\section{Acknowledgments}

This study was financially supported by a Grant-in-Aid for Scientific Research (C) from the Japan Society for the Promotion of Science.

\section{Conflicts of Interest}

The authors declare no conflict of interest.

\section{References}

1. Goto, Y.; Anzai, M.; Chiba, M.; Ohneda, A.; Kawashima, S. Clinical effects of xylitol on carbohydrate and lipid metabolism in diabetes. Lancet 1965, 2, 918-921.

2. Amo, K.; Arai, H.; Uebanso, T.; Fukaya, M.; Koganei, M.; Sasaki, H.; Yamamoto, H.; Taketani, Y.; Takeda, E. Effects of xylitol on metabolic parameters and visceral fat accumulation. J. Clin. Biochem. Nutr. 2011, 49, 1-7.

3. Ishii, H.; Takahashi, H.; Mamori, H.; Murai, S.; Kanno, T. Effects of xylitol on carbohydrate metabolism in rat liver treated with carbon tetrachloride or alloxan. Keio J. Med. 1969, 18, 109-114.

4. Mattila, P.T.; Svanberg, M.J.; Pökkä, P.; Knuuttila, M. Dietary xylitol protects against weakening of bone biomechanical properties in ovariectomized rats. J. Nutr. 1998, 128, 1811-1814.

5. Mattila, P.T.; Svanberg, M.J.; Knuuttila, M.L. Increased bone volume and bone mineral content in xylitol-fed aged rats. Gerontology 2001, 47, 300-305.

6. Mattila, P.; Knuuttila, M.; Kovanen, V.; Svanberg, M. Improved bone biomechanical properties in rats after oral xylitol administration. Calcif. Tissue Int. 1999, 64, 340-344.

7. Svanberg, M.; Mattila, P.; Knuuttila, M. Dietary xylitol retards the ovariectomy-induced increase of bone turnover in rats. Calcif. Tissue Int. 1997, 60, 462-466.

8. Brommage, R.; Binacua, C.; Antille, S.; Carrie, A.L. Intestinal calcium absorption in rats is stimulated by dietary lactulose and other resistant sugars. J. Nutr. 1993, 123, 2186-2194.

9. Barnes, S. The biochemistry, chemistry and physiology of the isoflavones in soybeans and their food products. Lymphat. Res. Biol. 2010, 8, 89-98.

10. Uesugi, T.; Toda, T.; Tsuji, K.; Ishida, H. Comparative study on reduction of bone loss and lipid metabolism abnormality in ovariectomized rats by soy isoflavones, daidzin, genistin, and glycitin. Biol. Pharm. Bull. 2001, 24, 368-372.

11. Breinholt, V.; Larsen, J.C. Detection of weak estrogenic flavonoids using a recombinant yeast strain and a modified MCF7 cell proliferation assay. Chem. Res. Toxicol. 1998, 11, 622-629.

12. Chang, Y.C.; Nair, M.G. Metabolism of daidzein and genistein by intestinal bacteria. J. Nat. Prod. 1995, 58, 1892-1896.

13. Setchell, K.D.; Borriello, S.P.; Hulme, P.; Kirk, D.N.; Axelson, M. Nonsteroidal estrogens of dietary origin: Possible roles in hormone-dependent disease. Am. J. Clin. Nutr. 1984, 40, 569-578.

14. Bolca, S.; Possemiers, S.; Herregat, A.; Huybrechts, I.; Heyerick, A.; de Vriese, S.; Verbruggen, M.; Depypere, H.; de Keukeleire, D.; Bracke, M.; et al. Microbial and dietary factors are associated with the equol producer phenotype in healthy postmenopausal women. J. Nutr. 2007, 137, 2242-2246. 
15. Setchell, K.D.; Clerici, C.; Lephart, E.D.; Cole, S.J.; Heenan, C.; Castellani, D.; Wolfe, B.E.; Nechemias-Zimmer, L.; Brown, N.M.; Lund, T.D.; et al. S-equol, a potent ligand for estrogen receptor $\beta$, is the exclusive enantiomeric form of the soy isoflavone metabolite produced by human intestinal bacterial flora. Am. J. Clin. Nutr. 2005, 81, 1072-1079.

16. Atkinson, C.; Frankenfeld, C.L.; Lampe, J.W. Gut bacterial metabolism of the soy isoflavone daidzein: Exploring the relevance to human health. Exp. Biol. Med. 2005, 230, 155-170.

17. Bowey, E.; Adlercreutz, H.; Rowland, I. Metabolism of isoflavones and lignans by the gut microflora: A study in germ-free and human flora associated rats. Food Chem. Toxicol. 2003, 41, 631-636.

18. Akaza, H.; Miyanaga, N.; Takashima, N.; Naito, S.; Hirao, Y.; Tsukamoto, T.; Fujioka, T.; Mori, M.; Kim, W.J.; Song, J.M.; et al. Comparisons of percent equol producers between prostate cancer patients and controls: Case-controlled studies of isoflavones in Japanese, Korean and American residents. Jpn. J. Clin. Oncol. 2004, 34, 86-89.

19. Frankenfeld, C.L.; Atkinson, C.; Thomas, W.K.; Goode, E.L.; Gonzalez, A.; Jokela, T.; Wahala, K.; Schwartz, S.M.; Li, S.S.; Lampe, J.W. Familial correlations, segregation analysis, and nongenetic correlates of soy isoflavone-metabolizing phenotypes. Exp. Biol. Med. 2004, 229, 902-913.

20. Turnbaugh, P.J.; Ley, R.E.; Mahowald, M.A.; Magrini, V.; Mardis, E.R.; Gordon, J.I. An obesity-associated gut microbiome with increased capacity for energy harvest. Nature 2006, 444, 1027-1031.

21. Salminen, S.; Salminen, E.; Koivistoinen, P.; Bridges, J.; Marks, V. Gut microflora interactions with xylitol in the mouse, rat and man. Food Chem. Toxicol. 1985, 23, 985-990.

22. Wang, X.L.; Hur, H.G.; Lee, J.H.; Kim, K.T.; Kim, S.I. Enantioselective synthesis of $S$-equol from dihydrodaidzein by a newly isolated anaerobic human intestinal bacterium. Appl. Environ. Microbiol. 2005, 71, 214-219.

23. Rafii, F.; Jackson, L.D.; Ross, I.; Heinze, T.M.; Lewis, S.M.; Aidoo, A.; Lyn-Cook, L.; Manjanatha, M. Metabolism of daidzein by fecal bacteria in rats. Comp. Med. 2007, 57, 282-286.

24. Mäkeläinen, H.S.; Mäkivuokko, H.A.; Salminen, S.J.; Rautonen, N.E.; Ouwehand, A.C. The effects of polydextrose and xylitol on microbial community and activity in a 4-stage colon simulator. J. Food Sci. 2007, 72, M153-M159.

25. Minamida, K.; Tanaka, M.; Abe, A.; Sone, T.; Tomita, F.; Hara, H.; Asano, K. Production of equol from daidzein by Gram-positive rod-shaped bacterium isolated from rat intestine. J. Biosci. Bioeng. 2006, 102, 247-250.

26. Salminen, E.K.; Salminen, S.J.; Porkka, L.; Kwasowski, P.; Marks, V.; Koivistoinen, P.E. Xylitol vs glucose: Effect on the rate of gastric emptying and motilin, insulin, and gastric inhibitory polypeptide release. Am. J. Clin. Nutr. 1989, 49, 1228-1232.

27. Mattila, P.T.; Svanberg, M.J.; Jämsä, T.; Knuuttila, M.L. Improved bone biomechanical properties in xylitol-fed aged rats. Metabolism 2002, 51, 92-96.

28. Svanberg, M.; Knuuttila, M. Dietary xylitol prevents ovariectomy induced changes of bone inorganic fraction in rats. Bone Miner. 1994, 26, 81-88.

29. Fujioka, M.; Uehara, M.; Wu, J.; Adlercreutz, H.; Suzuki, K.; Kanazawa, K.; Takeda, K.; Yamada, K.; Ishimi, Y. Equol, a metabolite of daidzein, inhibits bone loss in ovariectomized mice. J. Nutr. 2004, $134,2623-2627$. 
30. Ohta, A.; Uehara, M.; Sakai, K.; Takasaki, M.; Adlercreutz, H.; Morohashi, T.; Ishimi, Y. A combination of dietary fructooligosaccharides and isoflavone conjugates increases femoral bone mineral density and equol production in ovariectomized mice. J. Nutr. 2002, 132, 2048-2054.

31. Tousen, Y.; Ezaki, J.; Fujii, Y.; Ueno, T.; Nishimuta, M.; Ishimi, Y. Natural $S$-equol decreases bone resorption in postmenopausal, non-equol-producing Japanese women: A pilot randomized, placebo-controlled trial. Menopause 2011, 18, 563-574.

32. Shafer, R.B.; Levine, A.S.; Marlette, J.M.; Morley, J.E. Effects of xylitol on gastric emptying and food intake. Am. J. Clin. Nutr. 1987, 45, 744-747.

33. Yamakoshi, J.; Piskula, M.K.; Izumi, T.; Tobe, K.; Saito, M.; Kataoka, S.; Obata, A.; Kikuchi, M. Isoflavone aglycone-rich extract without soy protein attenuates atherosclerosis development in cholesterol-fed rabbits. J. Nutr. 2000, 130, 1887-1893.

34. Mäkinen, K.K.; Hämäläinen, M.M. Metabolic effects in rats of high oral doses of galactitol, mannitol and xylitol. J. Nutr. 1985, 115, 890-899.

35. Islam, M.S. Effects of xylitol as a sugar substitute on diabetes-related parameters in nondiabetic rats. J. Med. Food 2011, 14, 505-511.

36. Torok, V.A.; Ophel-Keller, K.; Loo, M.; Hughes, R.J. Application of methods for identifying broiler chicken gut bacterial species linked with increased energy metabolism. Appl. Environ. Microbiol. 2008, 74, 783-791.

37. Nagashima, K.; Hisada, T.; Sato, M.; Mochizuki, J. Application of new primer-enzyme combinations to terminal restriction fragment length polymorphism profiling of bacterial populations in human feces. Appl. Environ. Microbiol. 2003, 69, 1251-1262.

38. Nagashima, K.; Mochizuki, J.; Hisada, T.; Suzuki, S.; Shimomura, K. Phylogenetic analysis of $16 \mathrm{~S}$ ribosomal RNA gene sequences from human fecal microbiota and improved utility of terminal restriction fragment length polymorphism profiling. Biosci. Microflora 2006, 25, 99-107.

39. Walker, A.W.; Ince, J.; Duncan, S.H.; Webster, L.M.; Holtrop, G.; Ze, X.; Brown, D.; Stares, M.D.; Scott, P.; Bergerat, A.; et al. Dominant and diet-responsive groups of bacteria within the human colonic microbiota. ISME J. 2011, 5, 220-230.

40. Turnbaugh, P.J.; Ridaura, V.K.; Faith, J.J.; Rey, F.E.; Knight, R.; Gordon, J.I. The effect of diet on the human gut microbiome: A metagenomic analysis in humanized gnotobiotic mice. Sci. Transl. Med. 2009, doi:10.1126/scitranslmed.3000322.

41. De La Serre, C.B.; Ellis, C.L.; Lee, J.; Hartman, A.L.; Rutledge, J.C.; Raybould, H.E. Propensity to high-fat diet-induced obesity in rats is associated with changes in the gut microbiota and gut inflammation. Am. J. Physiol. Gastrointest. Liver Physiol. 2010, 299, G440-G448.

42. Reeves, P.G.; Nielsen, F.H.; Fahey, G.C., Jr. AIN-93 purified diets for laboratory rodents: Final report of the American Institute of Nutrition ad hoc writing committee on the reformulation of the AIN-76A rodent diet. J. Nutr. 1993, 123, 1939-1951.

43. Allain, C.C.; Poon, L.S.; Chan, C.S.; Richmond, W.; Fu, P.C. Enzymatic determination of total serum cholesterol. Clin. Chem. 1974, 20, 470-475.

44. Spayd, R.W.; Bruschi, B.; Burdick, B.A.; Dappen, G.M.; Eikenberry, J.N.; Esders, T.W.; Figueras, J.; Goodhue, C.T.; LaRossa, D.D.; Nelson, R.W.; et al. Multilayer film elements for clinical analysis: Applications to representative chemical determinations. Clin. Chem. 1978, 24, 1343-1350. 
45. Takayama, M.; Itoh, S.; Nagasaki, T.; Tanimizu, I. A new enzymatic method for determination of serum choline-containing phospholipids. Clin. Chim. Acta 1977, 79, 93-98.

46. Bligh, E.G.; Dyer, W.J. A rapid method of total lipid extraction and purification. Can. J. Biochem. Physiol. 1959, 37, 911-917.

47. Tamura, M.; Hori, S.; Nakagawa, H. Dihydrodaidzein-producing Clostridium-like intestinal bacterium, strain TM-40, affects in vitro metabolism of daidzein by fecal microbiota of human male equol producer and non-producers Biosci. Microflora 2011, 30, 65-71.

48. Matsuki, T. Procedure of DNA extraction from fecal sample for the analysis of intestinal microflora J. Intest. Microbiol. 2006, 20, 259-262.

(C) 2013 by the authors; licensee MDPI, Basel, Switzerland. This article is an open access article distributed under the terms and conditions of the Creative Commons Attribution license (http://creativecommons.org/licenses/by/3.0/). 